\title{
The Unique Realities of Roma Lgbti in Albania
}

\section{Mirjeta Ramizi}

PhD Student, Faculty of Social Studies in Tirana

\begin{abstract}
Roma LGBTI inequalities based on ethnicity, race, gender and sexual orientation have an intersectional character and build upon the intersection of these identity variables rather than having an aggregate factorial value, constitutes the major methodological-research question in this study. Understanding social structures, discrimination and disadvantage of LGBTI Roma in Albania involves scientific qualitative methodological tools in order to unveil the diversity, variations, differences and heterogeneity.

The lesbian, gay, bisexual, transgender and intersex Roma people in Albania tell complex histories of being, both, present in and excluded from the communities they live in. Being different is a reality and the efforts to feel part of a community, are ongoing and painful. The LGBTI Roma see the world first and foremost from the point of view of race, gender and sexual orientation. The findings show that violence and discrimination against the LGBTI Roma community are a wide-spread phenomenon and manifested in the most severe and traumatic forms.

The living stories of LGBTI Roma are rooted in the structural inequalities based on the intersection of sexual orientation, gender and ethnicity. LGBTI Roma in Albania are a "unique reality" which does not correspond and does not represent the reality of a Roma or LGBTI person. The research proves that from the methodological point of view in social sciences an illiterate gay Roma with low incomes is different from a gay illiterate and with low incomes (an illiterate + gay + Roma + low incomes $\neq$ from a gay + low incomes + illiterate).
\end{abstract}

Keywords: Roma, Intersectionality, Exclusion, Poverty, LGBTI.

\section{Introduction}

The LGBTI Roma realities, analysed through this research, sometimes resemble to some fragments of reality of LGBTI persons from the ethnic majority and sometimes with that of many people in different living circumstances. What distinguishes them from all the research groups in this study is the overlapping and depth of problems and living difficulties that they face with. The LGBTI Roma persons face discrimination and negligence when accessing medical care. Bullying of LGBTI Roma/Egyptian children and teenagers in neighbourhoods and schools, as well as the psychological violence, increase the dropout rate. Acts of violence are part of the reality of all the LGBTI Roma persons and several hate crimes based on the sexual orientation and gender identity have been identified during the in-depth interviews and living stories of this research study. Therefore, intensifying the efforts to protect lesbian, gay, bisexual, transgender and intersexual Roma from the acts of violence, discrimination and bullying by fully implementing the National Action Plan on LGBTI Persons 2016-2020 and by amending the Family Code to ensure legal recognition of the same sex partnerships, still remain a priority.

The LGBTI Roma constitutes one of the poorest groups in the Albanian society, which is poverty in its multi-dimensional sense. The respondents' profiles showed a human condition that is characterized from a sustainable or chronic deprivation of the necessary resources, skills, choices, safety and security and power to enjoy an adequate living standard and other civil, cultural, economic, political and social rights. Poverty among this community is caused from discrimination, like discrimination has also often been caused from the poverty of individuals themselves and among their families. On the other hand, poverty itself nourishes other inferiority and vulnerability situations, which create a closed vicious circle for LGBTI Roma individuals. Moral and sexual harassments and demeaning comments against the dignity and personality of an employee are forbidden by law. Despite the positive changes, the reality shows that LGBTI persons and, 
moreover, LGBTI Roma persons, face high levels of discrimination and humiliation from employers. None of the LGBTI Roma persons contacted during this research had a sustainable employment. The majority of the study group have provided for their living through small trade, by selling second hand clothes and items, assistance from friends, random works. Many of them also informed on sex activities against payment in order to survive. Use of alcohol and abuse with substances is a problem that emerged from the in-depth interviews with LGBTI Roma persons in this study. Such a problem deteriorates when the individuals become homeless. Homeless LGBTI Roma cases that use drugs and drink alcohol are at a higher level compared to the other populations of this study.

A different gender identity and sexual orientation, combined with the Roma background as an inferior minority in the Albanian society, based on the research findings, create the basis for victimization and discrimination from peers in the schools premises. In many cases, the latter has led to failure to be enrolled or attend school, and in the best scenario, to poor academic results of LGBTI Roma students. Poverty, unemployment, racism and homophobia, discrimination and stigma, abuse with substances as a mechanism to relieve stress, lack of a supportive system like the family, involvement in sexual activities as a survival means and health problems, are among the main reasons of a lack of adequate housing for LGBTI Roma individuals. Among other numerous factors, violence and hate against LGBTI Roma seems to be deeply rooted in the different appearance, outer look and behaviour. Abuse and use of substances, poverty, exposure towards violence during childhood, whether as a witness or victim, are some of the main factors that have been regularly connected to the physical violence and attacks against the intimate partner.

Every individual shall be entitled to live without stigma, discrimination, violence or persecution. The international legal framework on human rights imposes legal obligations to every state in order to ensure that all citizens enjoy their rights and participate equally in the society. However, the situation of hundreds of LGBTI Roma in Albania is very concerning, as they appear to face with severe violations of human rights. LGBTI Roma in Albania live in the remotest extremities of access to public services and face with negligent and refusing behaviour from the public institutions. The situation is worsened even further due to discrimination from the society, which converts into forms of emotional and physical violence given also their ethnicity as well as inferior sexual orientation and gender identity.

Hypothesis: "The intersection of ethnicity, gender and sexual orientation, shape a unique situation of LGBTI Roma persons in Albania, which is completely different from that of LGBTI persons ".

\section{Methodology}

The methodological approach of this study includes: 1) Collection and analyses of primary data using tools such as focus-groups and living stories with LGBTI Roma individuals, heterosexual Roma, non-Roma LGBTI and non-Roma heterosexual, as well as their thematic analysis, and 2) a desk review and analyses of secondary data. The population was divided into four groups for comparison and analyses: Group A- LGBTI Roma population; Group B- heterosexual Roma population; Group C- non-Roma LGBTI population; Group D- non-Roma heterosexual population. A total of 12 focus-groups have been held, of which four (4) with LGBTI people (Roma and non-Roma), four (4) with Roma community members and four (4) with nonRoma heterosexual population. A total of $112(\mathrm{n}=112)$ persons participated in the research study from all over Albania. Moreover, nine (9) in-depth living stories have been shared from LGBTI Roma individuals.

The study was conducted in four municipalities of Albania such as Tirana, Durres, Shkoder and Berat. The selection of these municipalities is based on several criteria, including also the geographical distribution of the selected population, thus representing the centre, north and south of Albania and the considerable numbers of Roma populations that are located. Individuals of 18 years of age and above were eligible to participate in the study.

Another aspect of the methodology is based on analysing the living stories as a starting point for intersectional empirical studies. The latter is related to two aspects, analysing the roots and paths of living stories and analysing the constructions of respect in everyday life in relation to the interconnection among ethnicity, gender and sexual orientation. For the interest of this intersectional study, the method of case studies has been used to identify new invisible groups, in the interconnection among categories (ethnicity, gender, sexual orientation and other variables), in order to discover the differences and complexity of 
experience embedded in that social status. The traditional categories have been firstly used to name unstudied groups in different parts of the interconnection, but the interest of this study has been mainly in unveiling the distinctions and differences within the group itself. Despite that the structures of gender, racial, sexual orientation inequality have an impact and must be studied, they do not fully explain the qualities and construction of the everyday complex status of a subject or a social group under study, notwithstanding the level of disaggregation (division as per the categories).

The sampling of individuals included in the focus-groups was random for group B and D of the population, whereas for group $\mathrm{A}$ and $\mathrm{C}$ it was intentional, through contacts and recommendations from some of the organizations that work for LGBTI community issues in Albania. The identification and inclusion of the individuals for the $\mathrm{A}$ and $\mathrm{C}$ samples population in the focus-groups and meetings on personal stories has been a challenge. During the focus-groups, the information has been recorded and then transcripted. The data has been analysed using the method of thematic analysis. This method included inductive analysis to identify the new topics arising from the data of personal stories and first focus-groups and deductive analysis to explore the topics identified beforehand and addressed in the focus-groups.

\section{Results}

Roma LGBTI related social inequalities and identities are based on ethnicity, race, gender and sexual orientation, have an intersectional character and build upon the interconnection of these identity variables rather than having an aggregate factorial value. This study tries to understand the social status, discrimination and disadvantage of LGBTI Roma in Albania through refined qualitative scientific methodological tools while unveiling the diversity, variations, differences and heterogeneity among LGBTI Roma themselves and comparison populations, such as Roma heterosexuals, LGBTI, non-Roma LGBTI population and non-Roma heterosexual population.

This research emerged as a need against the underestimation of some categories and characteristics of LGBTI in Albania, and due to the fact that some analysis generalize all LGBTI and build upon the characteristics, difficulties and priorities of a minority group of LGBTI, who mainly live in developed urban areas, are not a minority or do not belong to the Roma ethnicity, may have a high education attainment and belong to a specific economic, cultural category, etc.

Finding intersections and overlapping in different identity elements, like for e.g. between the ethnicity and sexual orientation, is subject of this research. We examined how different combinations of identity elements create various life experiences compared to other persons that, for example, share just a part of these identity elements and not all of them taken as a whole.

The intersectional analysis represents the most adequate research contextualized paradigm; an effort to fight homogenisation in studying LGBTI Roma, by conducting an in-depth analysis of all the variations such as gender, race, ethnicity, class, education attainment, age, economic and social category variable, etc., in order to thoroughly understand the social status of each LGBTI individual.

In her article, "The Complexity of Intersectionality" (Mc. Call. 2005), McCall has analysed three types of methodological approaches to study the multiple, interacting and complex social relations, thus to conduct intersectional analysis. These three methodological approaches are defined from the manner how they use the analysing categories to explore the complexity of intersectionality in the social life. These approaches include: the anti-categorical, inter-categorical and intra-categorical complexity. The methodology of first approach is based on destroying the analytical categories and this has been a successful approach as, generally, there is scepticism in using the categories altogether. The inter-categorical approach requires that the researchers adapt certain categories to confirm the inequality relations among various social groups as well as to explain the dimensions of inequality and differences among groups and within the groups themselves. The intra-categorical approach is applied in more thorough studies of a certain social or cultural group, which are more interested in the qualitative part of the categories. The authors that use this approach are mainly focused in certain social groups which are located in the marginalized and underestimated parts of the intersectionality. According to Dill (Dill. 2002), this targets those people that overcome the limits of traditionally built groups. 
As Anne Fausto-Sterling wrote back in 2000 in her work "Sexing the Body: Gender Politics and the Construction of Sexuality": "The artificiality of social categories may be enlightened in history with genealogical methods, in literature with deconstruction and in anthropology with the new ethnography. In any case, the wholeness of group sets that constitute a category is challenged. For example, the gender category, was first thought to comprise of men and women, but questions trying to understand what constitutes a men and what a women as well as the differences among them - is it the biological sex, and if so, what makes biologically a men and what a woman?- led toward the definition of new "social" groups, new in the sense of definition as such or/and in the sense of time when they were created or defined. Now we don't have only two genders any more, but there is an indefinite number of genders, we don't have only two sexes, but five sexes". (Fausto-Sterling. 2000).

Intersectionality of identities happens through the articulation of only one dimension of each category. Thus, for example, an Albanian Roma woman, educated and heterosexual, is placed in the interconnection of multiple categories (ethnicity, gender, sexual orientation, education attainment), but reflects only one dimension of each. The personal histories try to put the subjects under the full network of relations that determine their social position, but normally it is possible to position them (the subjects) just under the partial perspective of the particular social group under study (for example Roma women).

The intersectional analysis of Roma LGBTI is an analysis on multiple resources, among interacting sectors and variables of suppression and oppression. The awareness on intersectionality in analysing Roma LGBTI can help us to better know and judge the differences.

Intersectionality analyses the interrelated nature of the social categories such as race, class, gender, etc., intersected in Roma LGBTI realities in Albania as they are applied to an individual or group, which are considered to create overlapping and independent systems of discrimination or disadvantage. Intersectionality is an effort to make more in-depth analysis, paying attention to the differences, distinctions and specifics. As a research paradigm, intersectionality has provided a new thorough dimension of understanding gender, racial and sexual orientation, in the realities of Roma LGBTI in Albania.

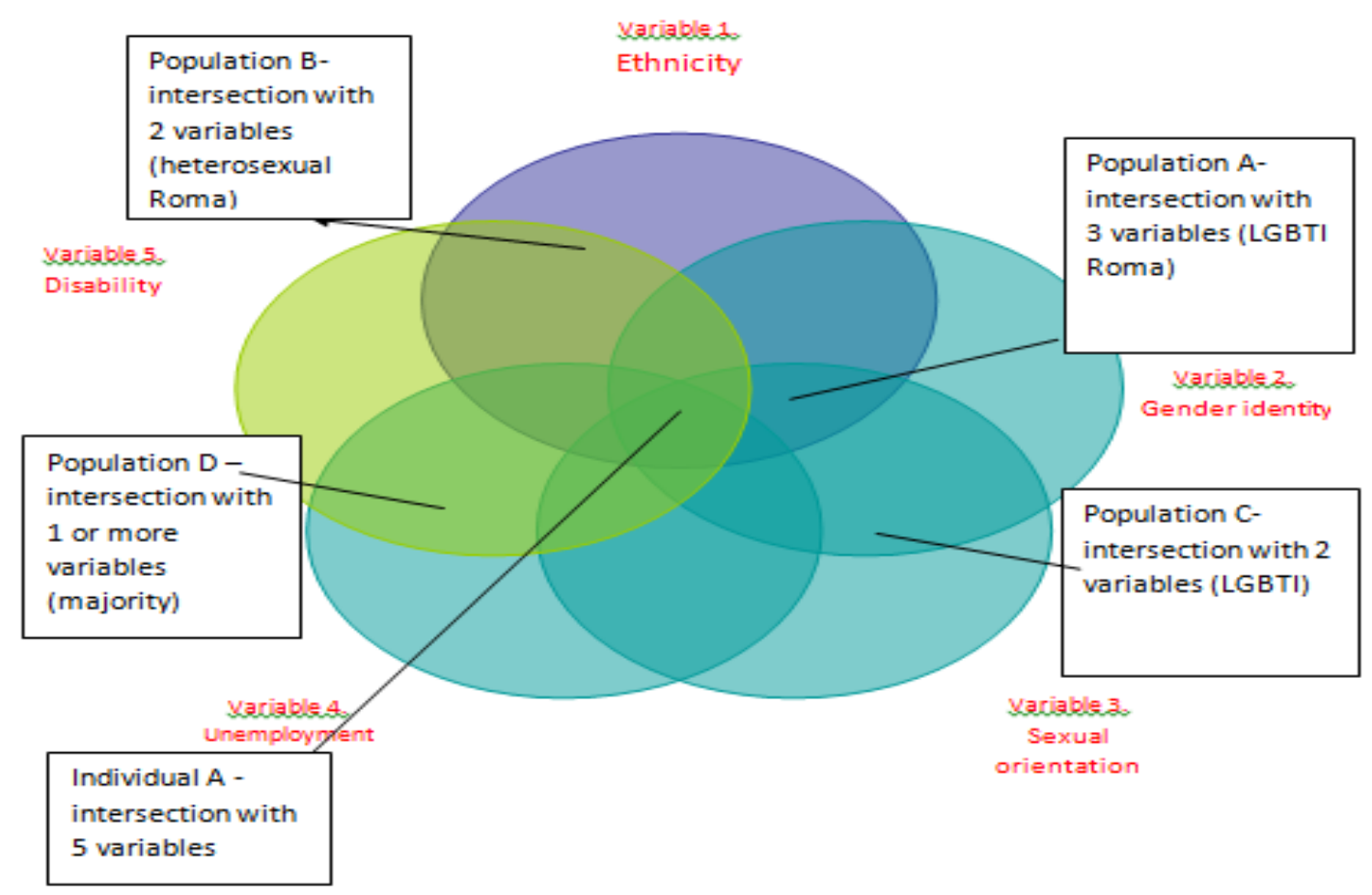

Figure 1: Intersectionality (interconnection) of identity variables

The LGBTI Roma constitutes one of the poorest groups in the Albanian society, which is poverty in its multi-dimensional sense. The respondents' profiles showed a human condition that is characterized from a sustainable or chronic deprivation of the necessary resources, skills, choices, safety and security and power to enjoy an adequate living standard and other civil, cultural, economic, political and social rights. Poverty 
among this community is caused from discrimination, like discrimination has also often been caused from the poverty of individuals themselves and among their families. On the other hand, poverty itself nourishes other inferiority and vulnerability situations, which create a closed vicious circle for LGBTI Roma individuals. It is clear that for a poor and homeless person it is very difficult to come out of poverty. On the other hand, poverty and lack of economic stability bring about several domino-effect difficulties in the life of persons, like inability to pay the rent, involvement in illicit activities, sex work, health problems, substance addiction, etc.

In health facilities, LGBTI persons are often subject to prejudicial reactions. Due to expecting these negative reactions, many LGBTI persons are reluctant to ask for medical assistance when needed. Moreover, many healthcare employees do not possess the required knowledge on how to address the needs of LGBTI persons. The LGBTI Roma persons have additional barriers due to being subject to added prejudices and discrimination because of their ethnic belonging. According to a study conducted by the group of authors listed below in 2015, there are relevant racial/ethnic differences interconnected with several important variables such as: the social-economic status, family status, different stress-causing elements or healthrelated issues, the use of substances, mental health problems, etc., which the sexual and gender minorities face with (Balsam, K. F., Molina, Y., Blayney, J. A., Dillworth, T., Zimmerman, L., \& Kaysen, D. 2015).

Meyer, one of the minority stress theory researchers, investigates the manner how drivers or causes of stress can have different results on the health of individuals that belong to the minorities compared to those from the majority. According to Meyer, "the minority stress processes in lesbian, gay and bisexual populations are based on stress-related factors and different handling mechanisms, and their positive or negative impact leads to mental health results." The model describes the processes of stress, including experiences of prejudice, refusal, identity concealment, internalized homophobia and handling mechanisms (Meyer. 2003). Homophobia, sexual stigma, racism or discrimination that might arise from the surrounding environment cause high levels of stress and require for an individual to adapt. All this entire process leads to consequences in the health of individuals. Whereas HIV-positive LGBTI Roma individuals get stigmatized due to their situation, the HIV-negative ones live with the possibility of getting infected due to unprotected sex, use of substances or multiple sex partners and have a potential for high levels of psychological disorders and mental health issues. Stigmatization from the society and risky behaviours increase when a LGBTI community member is also a member of a racial/ethnic minority group. LGBTI Roma persons suffer from additional issues of mental health such as depression, anxiety and post-traumatic stress disorder, coming as a result of the process of internal development of the gender, ethnic and sexual identity, but also due to the direct effect of discrimination, violence and hatred from the society. According to the respondents, the dark skin colour and manner of dressing, which shows a status of poverty, are the first physical characteristics that create an inferior status of the individual in the society. There is a lot of discrimination within the Roma and Egyptian community itself for LGBTI Roma individuals. Lack of information, family support, social exclusion and discrimination from the Roma community itself, often cause a serious of problems with mental health for LGBTI Roma persons.

"Recently, in our neighborhood we have learned about two Roma gay persons. It has been a huge problem. They have suffered from prejudice. They have stayed alone. They also suffered from depression. One of them has left, vanished and, maybe, his family communicates with him. However, within the community, they have never accepted to keep contacts. The other got sick and is still at the hospital with mental problems. The majority of people here think that if you get close to them, you will become like them, you should not touch them..." mentioned during a focus group in a Roma community.

The incidents of attacks or sexual violence were observed and the findings from deep stories are really shocking. Almost all LGBTI Roma persons have suffered acts of rape or sexual violence in their childhood and adult age. Such events are deeply rooted in the awareness and identity development of the LGBTI Roma persons. Moreover, these events have left severe health consequences in the life of victims, such as HIV or Hepatitis B infections, etc.

Use of alcohol and abuse with substances is a problem that emerged from the in-depth interviews with LGBTI Roma persons in this study. Such a problem deteriorates when the individuals become homeless. 
Homeless LGBTI Roma cases that use drugs and drink alcohol are at a higher level compared to the other populations of this study.

The official figures speak about 40-50 thousand users of all drugs, meanwhile 7-8 thousand of them do strong drugs like heroine and need treatment. ${ }^{1}$ Since 13 years, "Aksion Plus" organization is administering the methadone treatment in Tirana for about 550 clients that take the therapy every day. Nation-wide, as per the statistics of the same organization, there are about 700 "clients" using methadone maintenance treatment, of which about $10 \%$ belong to the LGBTI Roma community (Aksion Plus. 2019).

Based on the in-depth interviews and the findings of the focus-groups, during the last years there has been an increasing trend in drug use among youth in general and, even more, among the LGBTI Roma. The findings of this study show that abuses with heroine are more prevalent among the Roma/LGBTI respondents, more than among other comparison groups. Other studies show that among youth, especially vulnerable ones in Albania, heroine is the most popular drug to be injected, whereas cannabis is wide-spread among youth in high schools. The number of heroine users is increasing rapidly. The majority inject it. As the age of starting heroine for the control population has lowered at the ages of 14 and 16, the number of LGBTI Roma and Egyptians injecting drugs and having health-related problems has increased. This mainly happens in conjunction with problems of the individual in relation to the family and mostly in cases of users in street situation.

Based on the findings from the focus-groups and interviews, a considerable number of LGBTI Roma has been once in their life a drug user and many of them receive methadone maintenance treatment. There are at least three identified cases of LGBTI Roma persons that have been punished and sentenced to prison due to being caught with drugs.

More work should be put to the information, counselling, education of youth, testing for HIV, syphilis, hepatitis $\mathrm{B}$ and $\mathrm{C}$, condoms and training of the medical and psycho-social staff on the manner of communication and provision of services for LGBTI Roma persons. The state should become more active in the area of reducing damages in the prison facilities and ensure the availability of financial resources and professional staff.

LGBTI Roma individuals show very low rates of education enrolment and progress. Illiteracy is another concerning phenomenon for this community due to failure to attend school at all. A different gender identity and sexual orientation, combined with the Roma background as an inferior minority in the Albanian society, based on the research findings, create the basis for victimization and discrimination from peers in the schools premises. In many cases, the latter has led to failure to be enrolled or attend school, and in the best scenario, to poor academic results of LGBTI Roma students.

Poverty, unemployment, racism and homophobia, discrimination and stigma, abuse with substances as a mechanism to relieve stress, lack of a supportive system like the family, involvement in sexual activities as a survival means and health problems, are among the main reasons of a lack of adequate housing for LGBTI Roma individuals.

The LGBTI Roma population investigated through this research appears to be homeless in total. In the absence of a social capital and due to exclusion in many cases from their community and family, a good part of them live in shacks or in the streets. Failure of support systems, such as the family or care institutions, orphanages or paediatric hospitals, based on the interview narratives, has allowed for development of traumatic experiences of sexual abuses in these subjects since a very early age, making their reality and housing situation more severely painful.

"When I was little, I got very sick and I was hospitalized in the children's hospital where I stayed for a long time. My mother abandoned me and left me there due to poverty. After some months I began to feel better and kept staying there because the doctors didn't know where to take me. For them I was simply a little boy without a family. During this time the husband of a staff member began to abuse with me. It was horrible. After some time the staff understood what was going on and I was dismissed to the streets...nowhere to go...I joined with a group of homeless people. There I experienced the tragedy of my life. A man shut me in a

${ }^{1}$ Stated in the annual report of the "Aksion Plus" NGO 
basement and systematically abused with me, for several consecutive days, without any food or water. Even I do not know how I survived...the police found me and released me." said L.L. during the interview.

Discrimination, racism, systematic disparity and historical trauma among ethnic/racial minorities with a different sexual orientation and gender identity are prevalent and more severe in experience compared to the dominant ethnic groups or LGBTI groups.

Among other numerous factors, violence and hate against LGBTI Roma seems to be deeply rooted in the different appearance, outer look and behaviour. Abuse and use of substances, poverty, exposure towards violence during childhood, whether as a witness or victim, are some of the main factors that have been regularly connected to the physical violence and attacks against the intimate partner. Some studies have also found connections between the level of accumulated stress among minorities in the form of internalized homophobia and the frequency of discrimination based on sexual orientation as factors related to physical violence and attacks. However, this complex relation among these factors is less clear and studied.

The findings of this research reveal that experiences of violence differ depending from race, gender, sexual orientation and poverty. The LGBTI respondents were as clear as the LGBTI majority persons when determining if violence was based on their sexuality, concluding that in fact the key variable stimulating violence among abusers was sexual orientation. Meanwhile, the forms of violence reported from LGBTI Roma/Egyptians are extremely more severe compared to all other populations in the research.

\section{Discussion}

Norms within a specific ethnic subculture can dramatically shape the way sexuality is perceived by individuals (Greene, 1994). In some communities, heterosexism is so entrenched that gay, lesbian, bisexual and intersexual identities may not even be considered an option (Cheng, 2011; Greene, 1994). Heterosexism and homophobia in ethnic communities like the Roma people, impede them from coming out (Rosario, Schrimshaw, \& Hunter, 2004).

The LGBTI Roma have three possibilities regarding the integration of their communities: 1. identify with numerous groups; 2. identify with one group only, excluding others; and 3. identify with a group at a certain moment in time. The majority of LGBTI Roma in Albania, who have openly expressed their gender identity and sexual orientation, i.e. have come out, feel themselves mostly identified with the LGBTI community than the Roma one. However the majority of them say that it is impossible to enter into a romantic relationship (apart from paid sexual relations) with a partner from the mainstream population due to racial discrimination. An exception from this group is the lesbians, whose partners, according to the findings of this study, are mainly from the mainstream population. According to this approach, the LGBTI Roma must live within three communities or realities defined in a strict and independent manner: LGBTI community, Roma community and the society in general. While each community provides the fundamental needs to the individual, joining these spaces in one reality may bring serious consequences. It takes an ongoing effort to keep oneself in three different worlds, where each of them is not able to support important aspects of the life of a person. The explicit consequences impede the ability of an individual to adapt and to achieve the personal potentials.

The research showed that the education, skills and qualification of Roma LGBTI do not meet the requirements of the labor market. These are among the key links that need to be improved to get this group out of the poverty cycle. In addition to education, policies should focus on the job skills and qualification of this group through training for professions that are actually required in the formal labor market and where employment opportunities exist. In this case, vocational training centers should work closely with employment offices, local government, chambers of commerce, business associations, etc. Local government can influence the employment of Roma LGBTI by reducing taxes on businesses that employ them or by subsidizing their income generation activities. Qualitative data from this research show that the lack of employment in the formal sector pushes Roma LGBTI in the informal sector, in those jobs that are not taken over by the rest of society.

Roma LGBTI in Albania experience more discrimination, poverty and exclusion, which in turn leads to instability in housing and increased psychological and emotional distress and difficulty. With an increased layer of discrimination, due to ethnicity, Roma people faced additional barriers to access safe and 
appropriate housing. Policies and interventions addressing issues of race and gender and sexual orientation should eliminate the combination of anti-LGBTI and racial discrimination and the structural barriers that fuel discrimination and exclusion, so that basic public services such as education, employment, health and housing can be accessed by all Roma LGBTI individuals.

Services for people with intersected identities, such as Roma LGBTI, should include elements that respect gender identity, sexual orientation, and that also have a historical and ethnic knowledge of the targeted populations, while also adapting services toward the client's cultural background. They need to be "integrated", addressing both sectoral issues (education, employment, housing, etc.) and adapting holistically to the intertwined needs and identities of marginalized groups.

\section{References}

[1.] Balsam, K. F., Molina, Y., Blayney, J. A., Dillworth, T., Zimmerman, L., \& Kaysen, D. (2015). Racial/ethnic differences in identity and mental health outcomes among young sexual minority women. Cultural diversity \& ethnic minority psychology, 21(3), 380-390. doi:10.1037/a0038680

[2.] Bandura, A. (1986). Social foundations of thought and action: A social cognitive theory. Englewood Cliffs, NJ: Prentice-Hall

[3.] World Bank. (2018). Summary on Poverty and Equality in Albania

[4.] BE, UNDP and World Bank. (2017). Roma at a glance

[5.] Bilodeau, B. L. (2005). Beyond the gender binary: A case study of two transgender students at a Midwestern university. Journal of Gay and Lesbian Issues in Education. Retrieved from Academic Search Complete.

[6.] Bilodeau, B. L. (2009). Genderism: Transgender students, binary systems, and higher education. Saarbrucken, Germany: VDM Verlag

[7.] Bowleg, Lisa. (2008). When Black + Lesbian + Women $\neq$ Black Lesbian Woman: The Methodological Challenges of Qualitative and Quantitative Intersectionality Research

[8.] Bussey, K., \& Bandura, A. (1999). Social cognitive theory of gender development and differentiation. Psychological Review, 1999, Vol. 106, No. 4, 676-713. Retrieved from American Psychological Association, Inc. 0033-295X/99/S3.00

[9.] Cass, V. C. (1984). Homosexual identity formation: Testing a theoretical model. The Journal of Sex Research, 20, 143-167

[10.] CEIC. (2019). https://www.ceicdata.com/en/indicator/albania/unemployment-rate

[11.] Cheng, P. S. (2011). Gay Asian Masculinities and Christian Theologies. Crosscurrents, 540- 548

[12.] Cochran, S.D., Mays, V.M., \& Sullivan, J.G. (2003). Prevalence of mental disorders, psychological distress, and mental health services use among lesbian, gay and bisexual adults in the United States. Journal of Consulting and Clinical Psychology, 71, 53-61

[13.] Denis, Ann. (2011). Intersectional Analyses: A contribution of Feminism to Sociology. SAGE

[14.] ERA. (2018) Written Contribution to the 3rd Cycle of UPR Review of Albania

[15.] Fausto-Sterling, Anne. (2000). Sexing the Body: Gender Policies and Constructions of Sexuality]. New York: Basic Books

[16.] OSFA. (2012). Ethnographic pieces. Tiranë

[17.] Fuss, Diana. (1991). Inside/ Out: Lesbian Theories, Gay Theories. New York: Routledge

[18.] Greene, B. (1994). Ethnic-Minority Lesbians and Gay Men: Mental Health and Treatment Issues. Journal of Consulting and Clinical Psychology, 62(2), 243-251

[19.] Hancock Ange-Marie. (2007). When multiplication doesn't equal quick addition: Examining intersectionality as a research paradigm. Perspectives of Politics

[20.] Hamilton, C.J., \& Mahalik, J.R. (2009). Minority stress, masculinity, and social norms predicting gay men's health risk behaviours. Journal of Counselling Psychology, 56, 132-141

[21.] INSTAT. (2019). Income and Living Conditions in Albania. http://www.instat.gov.al/en/themes/social-condition/income-and-living-conditions-inalbania/publication/2019/income-and-living-conditions-in-albania-2017-2018/

[22.] National Democratic Institute. (2015) Survey on the public opinion on LGBTI issues. https://www.ndi.org/LGBTI_Balkans_poll 
[23.] Jamil, O. B., Harper, G. W., \& Fernandez, M. I. (2009). Sexual and ethnic identity development among gay-bisexual-questioning (GBQ) male ethnic minority adolescents. Cultural Diversity and Ethnic Minority Psychology, 15, 203-214. doi: 10.1037/a0014795

[24.] Levitas, R., Pantazis, C., Fahmy E., Gordon, D., Lloyd E., Patsios, D. (2007). Multidimensional analyses of social exclusion. University of Bristol

[25.] Marcia, J. E. (1966). Development and validation of ego-identity status. Journal of Personality and Social Psychology, 3, 551-558

[26.] Marcia, J.E. (1991). Identity and self-development. In R. Lerner, A. Peterson, \& J. Brooks-Gunn (Eds.), Encyclopaedia of adolescence(Vol.1). New York: Garland

[27.] McCall, L. (2005). The Complexity of Intersectionality. Signs: Journal of Women, Culture and Society 30, no. 3: 1771-1800

[28.] Meyer, I.H. (2003). Prejudice, social stress, and mental health in lesbian, gay and bisexual populations: Conceptual issues and research evidence. Psychological Bulletin, 129, 674-697. doi:10.1037/0033-2909.129.5.674

[29.] Mike C. Paret. (2013). Approaches to Research on Intersectionality: Perspectives on Gender, LGBT, and Racial/Ethnic Identities. Sex Roles 68

[30.] Morales, E. (1990). Ethnic minority families and minority gays and lesbians

[31.] M. V. Lee Badgett, Ph.D. (2014). The Economic Cost of Stigma and the Exclusion of LGBT People: A Case Study of India.

http://documents.worldbank.org/curated/en/527261468035379692/pdf/940400ËP0Box380usion0of0L GBT0People.pdf

[32.] Papa, J., \& Keskine, I. (2017). Roma returnees: "Neither here nor there"

[33.] Parks CA, Hughes TL, Matthews AK. (2004). Race/ethnicity and sexual orientation: Intersecting identities. Cultural Diversity and Ethnic Minority Psychology. 2004;10:241-254. doi: 10.1037/10999809.10.3.241

[34.] Phinney, J. S. (1990). Ethnic identity in adolescents and adults: A review of research. Psychological Bulletin, 108, 499-514

[35.] Phinney, J. S. \& Ong, A.D. (2007). Conceptualization and measurement of ethnic identity: Current status and future directions. Journal of Counselling Psychology, 54, 271-281

[36.] Ragin, Charles C. (2000). Fuzzy-Set Social Science. University of Chicago Press

[37.] Ragins B, Cornwell JM, Miller JS. (2003) Heterosexism in the workplace: Do race and gender matter? Group \& Organization Management. 2003;28:45-74. doi: 10.1177/1059601102250018

[38.] Rosario, Schrimshaw, Hunter. (2004). Ethnic/Racial Differences in the Coming-Out Process of Lesbian, Gay, and Bisexual Youths: A Comparison of Sexual Identity Development Over Time. Cultural Diversity and Ethnic Minority Psychology, 10(3), 215-228

[39.] Rosario, Schrimshaw, Hunter and Braun. (2006). Sexual Identity Development among Gay, Lesbian, and Bisexual Youths: Consistency and Change Over Time. J Sex Res. 2006 February ; 43(1): 46-58. doi:10.1080/00224490609552298

[40.] Smith, E. J. (1991). Ethnic identity development: Toward the development of a theory within the context of majority/minority status.

[41.] UNDP/BB/EC. (2011). Socio-economic needs assessment report. http://www.al.undp.org/content/albania/en/home/library/poverty/roma-needs-assessment-report/ , f. $24-25$. 